\title{
In silico analyses of CD14 molecule reveals significant evolutionary diversity, potentially associated with speciation and variable immune response in mammals
}

\author{
Olanrewaju B Morenikeji ${ }^{1}$, Bolaji N Thomas ${ }^{\text {Corresp. } 1}$ \\ ${ }^{1}$ Department of Biomedical Sciences, Rochester Institute of Technology, Rochester, NY, United States of America \\ Corresponding Author: Bolaji N Thomas \\ Email address: bntsbi@rit.edu
}

Cluster differentiation gene (CD14) is a family of monocyte differentiating genes that works in conjunction with lipopolysaccharide binding protein (LBP), forming a complex with TLR4 or LY96 to mediate innate immune response to pathogens. In this paper, we used different computational methods to elucidate the evolution of CD14 gene coding region in 14 mammalian species. Our analyses identified leucine rich repeats (LRRs) as the only significant domain across the CD14 protein of the 14 species, presenting with frequencies ranging from 1-4. Importantly, we found signal peptides located at mutational hotspots demonstrating this gene is conserved across these species. Out of the 10 selected variants analyzed in this study, only 6 were predicted to possess significant deleterious effect. Our predicted protein interactome showed a significant varying protein-protein interaction with CD14 protein across the species. This may be important for drug target and therapeutic manipulation for the treatment of many diseases. We conclude that these results contribute to our understanding of the CD14 molecular evolution, which underlays varying species response to complex disease traits. 
1 In silico analyses of CD14 molecule reveals significant evolutionary

2

3

4

5

6

7

8

9

10

11 Olanrewaju B. Morenikeji: obmhst@rit.edu

12 Bolaji N. Thomas: bntsbi@rit.edu

13

14

15

16

17

18

19

20

21

22

\section{3}

4 *Corresponding author:

Dr. Bolaji N. Thomas

Department of Biomedical Sciences

17 Rochester Institute of Technology

8153 Lomb Memorial Drive

19 Rochester NY 14623

20 Office: (585) 475-6382

21 Fax: (585) 475-5809

22 Email: bntsbi@rit.edu

\section{diversity, potentially associated with speciation and variable}

\section{immune response in mammals}

\author{
Olanrewaju B. Morenikeji, Bolaji N. Thomas
}

Department of Biomedical Sciences, Rochester Institute of Technology, Rochester NY, United

States of America 


\section{Abstract}

24 Cluster differentiation gene (CD14) is a family of monocyte differentiating genes that works in

25

26

27 conjunction with lipopolysaccharide binding protein (LBP), forming a complex with TLR4 or LY96 to mediate innate immune response to pathogens. In this paper, we used different computational methods to elucidate the evolution of CD14 gene coding region in 14 mammalian species. Our analyses identified leucine rich repeats (LRRs) as the only significant domain across the CD14 protein of the 14 species, presenting with frequencies ranging from 1-4. Importantly, we found signal peptides located at mutational hotspots demonstrating this gene is conserved across these species. Out of the 10 selected variants analyzed in this study, only 6 were predicted to possess significant deleterious effect. Our predicted protein interactome showed a significant varying protein-protein interaction with CD14 protein across the species. This may be important for drug target and therapeutic manipulation for the treatment of many diseases. We conclude that these results contribute to our understanding of the CD14 molecular evolution, which underlays varying species response to complex disease traits. 
46

47

48

\section{Introduction}

Cluster of differentiation 14 (CD14) gene is a surface differentiation antigen preferentially expressed on mammalian monocytes, neutrophils, macrophages, and plasma cells (Baumann et al., 2010; Tang et al., 2017). It encodes a protein that is important for initiating a robust immune response against microbial pathogens by mediating innate immune response, in concert with several other proteins. It is a co-receptor with Toll-like receptor-4 (TLR4) to activate several intracellular signaling pathways that lead to the synthesis and release of inflammatory cytokines, antimicrobial peptides, chemokines, and other co-stimulatory molecules which in turn interact with the adaptive immune system (Hartel et al., 2008). Comparative studies have shown that two or more proteins can have common evolutionary origin thereby sharing structural and functional characteristics (Kanduc 2012). CD14 molecule exists in two forms: soluble (sCD14) or membrane-bound (mCD14) (Panaro et al., 2008; Xue et al., 2012). There are multiple variants of the CD14 molecule that are encoded by the same protein due to alternative splicing and as such has been mapped to varying chromosomal locations in different species. For example, it is mapped to chromosome 5 in humans, chromosome 7 in cattle and chromosome 18 in mouse (Ferrero et al., 1990; Le Beau et al., 1993; Ibeagha-Awemu et al., 2008).

Studies in human, mouse, cattle and sheep have shown that CD14 is significantly involved in innate immunity, playing major roles in susceptibility to tuberculosis, trypanosomosis, malaria and other bacterial infections (Sugawara et al., 2003; Ibeagha-Awemu et al., 2008; Xue et al., 2012; Ojurongbe et al., 2017). Other published reports have shown that there is a higher susceptibility to Mycobacterium tuberculosis infection in CD14 transgenic mice compared to the wild type (Reiling et al., 2002; Weiland et al., 2008). Likewise, single nucleotide polymorphisms 
69 (SNPs) in CD14 gene have been associated with higher susceptibility in many disease instances

70 (Oakley et al., 2009; Liu et al., 2012; Xue et al., 2012; Zanoni and Granucci, 2013; Thomas et

71 al., 2015; Xue et al., 2017). In fact, Song et al. (2014) reported how genetic heterozygosity

72 modulate disease resistance and progression in cattle infected with bovine tuberculosis.

73 Furthermore, comparative studies have shown that organism relatedness can be traced through

74 their pattern of genetic divergence (Kanduc, 2012; De Donato et al., 2017; Peters et al., 2018).

Several sequence-based methods and tools have been developed to glean evolutionary

77 information in related species via amino acids sequence variation and conservation of

homologous proteins through multiple sequence alignment (MSA) (Hepp et al., 2015, Peters et

al., 2018). Similarly, other computational methods are available to identify SNP variation within and between amino acid sequences in multiple species, which possibly affecting the stability and functionality of such proteins (Ng and Henikoff, 2006; Yue and Moult 2006; Hepp et al., 2015). Many of these tools can predict the effect of SNP occurrence in protein sequences to determine whether they are disease related, deleterious or neutral. Comparative genomics therefore is a powerful tool to elucidate variants and effects among multiple species in order to detect diseases associated with variations. Variations in amino acid sequence have the ability to alter protein structure and functions like ligand binding, protein folding, impaired intracellular transport and reduced stability (Zeron-Medina et al., 2013; Morisseau et al., 2014; Valastyan and Lindquist 88 2014).

Due to the significance of CD14 gene in several disease cases in humans and other species, in

91 addition to its considerable involvement in innate immunity, we hypothesize that there might be 
92 evolutionary patterns of similarity and diversification that occurred during speciation, which is

93 important for comparative immune and disease studies in different species. To this end, we

94 carried out a detailed comparative study of CD14 protein in 14 mammalian species to elucidate

95 the evolutionary basis for conserved regions, active sites and mutational hotspots, which could

96 lead to novel disease phenotypes. In addition, we examine the diversification in CD14 protein

97 interactions within and across the species, which could be explored for therapeutic development

98 or drug design.

\section{Materials and Methods}

Sequence retrieval and multiple sequence alignment

102 Complete CD14 amino acid sequences of 13 mammals were retrieved from UniProtKB/Swiss-

103 Prot (https://www.uniprot.org/uniprot/?query=CD14\&sort=score) database. The sequences were

104 retrieved for human (P08571), rat (Q63691), mouse (P10810), cattle (Q95122), rabbit (Q28680),

105 monkey (B3Y6B8), gorilla (G3R4C0), sheep (W5QJA2), horse (F6VK89), pig (A7BG66),

106 buffalo (A0A2R4SDF9), chimpanzee (B3Y6B4) and yak (L8I9P7). The amino acid sequence for

107 goat (ABE68725.1) was retrieved from GenBank. We performed sequence alignment with the

108 Multalin software (http://multalin.toulouse.inra.fr/multalin/), which does a simultaneous

109 alignment of biological sequences with hierarchical clustering. To examine similarity between

110 the sequences, we used SIAS (Sequence Identity And Similarity,

111 http://imed.med.ucm.es/Tools/sias.html) with default BLOSUM62 scoring matrices.

112 Evolutionary tree was constructed from the sampled species through Phylogeny.fr

113 (http://www.phylogeny.fr/index.cgi) online program. 


\section{Comparative physicochemical properties of amino acid sequence in the CD14 molecule}

116 The biochemical properties of the amino acids from the 14 mammalian species were computed

117 with ProtParam (www.expasy.org/protparam/). The following properties were computed for each

118 sequence: aliphatic index, which defines the relative volume of a protein occupied by alanine,

119 valine, isoleucine, and leucine; instability index, which estimates the protein stability based on

120 the amino acid composition; protein net charge, which can be positive, negative or neutral based

121 on the amino acid composition in the protein; molecular weight; grand average of hydropathicity

122 (GRAVY), which determines the hydrophobicity of a protein from the aliphatic side chain; and 123 isoelectric point $(\mathrm{pI})$, which is the $\mathrm{pH}$ at which the protein net charge is equal to zero.

\section{Functional analysis, motif scanning and prediction of signal peptides}

126 We performed functional analysis on the protein sequences in order to classify them in to super

127 families, predict domains, repeats and find important sites that may be relevant in evolution. We

128 scanned for the motif signatures among the amino acid sequences with the combined use of

129 ScanProsite (https://prosite.expasy.org/) (Sigrist et al., 2010) and InterPro, an online program

130 that analyzes protein sequences and classification (https:/www.ebi.ac.uk/interpro/). The

131 HAMAP profiles, PROSITE patterns, Pfam global models and PROSITE profiles were all

132 included in the search. Sequence logo of the identified conserved domain in the CD14 protein

133 among the 14 mammalian species was constructed with WebLogo

134 (http://weblogo.berkeley.edu/logo.cgi), to show the graphical view of the region containing the 135 conserved amino acid among the species. Furthermore, we predicted the cleavage sites and the 136 presence of signal peptides in CD14 protein from the 14 mammalian species using SignalP 5.0

137 server (http://www.cbs.dtu.dk/services/SignalP/), which uses recurrent neural network 
138 architecture and deep convolution to classify signal peptides into lipoprotein signal peptides,

139 secretory signal peptides or Tat signal peptides. In order to gain a better understanding of the

140 localization of the protein in each species, we predicted subcellular localizations of CD14 protein

141 using Neural Networks algorithm on DeepLoc-1.0 server

142 (http://www.cbs.dtu.dk/services/DeepLoc/), and the construction of the subcellular pathway

143 hierarchical tree.

144

\section{Prediction analysis of amino acid substitution}

146 The effect of the amino acid substitution was predicted using the combination of SIFT (Sorting

147 Intolerance from Tolerance), PANTHER (Protein ANalysis THrough Evolutionary Relationship)

148 and PROVEAN (Protein Variation Effect Analyzer). Briefly, we used human CD14 amino acid

149 sequence to query the multiple sequence alignment of other mammalian species in this study

150 using SIFT which predict the tolerance or deleterious effect of substitutions for each position in

151 the query sequence. Any position with probability less than 0.05 is classified as deleterious, as

152 previously described (Bendl et al., 2014; Choi and Chan 2015). We selected a total of 10 variants

153 from the mutational hotspots as predicted by SIFT and further estimate the likelihood of the

154 selected variants and their effects on protein function through PROVEAN and PANTHER.

155

156

Prediction of protein interactome with CD14 protein in different species

157 In order to establish specific interaction of the CD14 protein with other molecules as a result of

158 biochemical events during speciation, we used the retrieved CD14 amino acid sequence from each

159 mammalian species in this study to predict its association with other protein groups and generate

160 different networks using STRING, a database that predicts protein-protein interactions 
161 (https://string-db.org/). This is important in order to examine the diversity shaped by evolution in

162 the association of CD14 gene with other molecules in different organisms. Venn diagrams were

163 constructed for the comparison and visualization of overlapping protein-protein interaction (PPI)

164 among different species using two web-based applications

165 (http://bioinformatics.psb.ugent.be/software/details/Venn-Diagrams and

166 http://bioinfogp.cnb.csic.es/tools/venny/)

167

168 Results

169 Comparative analysis and sequence evolutionary trace

170 In this study, we examined the evolutionary pattern of CD14 protein sequences in 14 mammalian

171 species. The alignment is conserved within two groups separated into ruminants and non-

172 ruminants. The multiple sequence alignment identified leucine (L), aspartic acid (D), lysine (K),

173 glutamic acid (E), valine (V), glycine (G), serine $(\mathrm{S})$ and asparagine $(\mathrm{N})$ as evolutionarily

174 conserved amino acid residues, while others like proline $(\mathrm{P})$, glutamine $(\mathrm{Q})$, methionine $(\mathrm{M})$,

175 alanine (A), phenylalanine (F), isoleucine (I) and threonine (T) were evolutionarily varied. The

176 CD14 protein sequence demonstrates significant variability in both percentage identity and

177 similarity across the 14 species, despite the common evolutionary origin (Figure 1, 2). The

178 percentage identity of CD14 protein in monkey, gorilla, chimpanzee and human was similar

179 while gorilla shares the closest identity with human (Table 1). Among the ruminants, cattle and

180 yak share the closet similarity compared to buffalo, sheep and goat, although the phylogenetic

181 tree suggests that goat is distantly related. While mouse and rat cluster with the same origin, the

182 analysis show that they share less identity (7.4\%) and similarity (13.4\%). Rabbit, horse and pig

183 are distantly apart from other species, as they do not share high conservation (Table 1, Figure 2). 
184 In all, the sequence of CD14 protein in goat and horse share the least identity $(6.7 \%$ and $6.9 \%$ for 185 goat and horse respectively) and similarity (9.9\% and $13.2 \%$ for goat and horse respectively) 186 with human.

187

\section{Physicochemical properties at the CD14 promoter region}

189

190

191

192

193

194

195

196

197

198

199

200

201

202

203

204

205

206

ProtParam tool (www.expasy.org/protparam/) was used to compute the physical and chemical properties of CD14 amino acid sequences among the 14 species (Table 2). The aliphatic index of all the species is generally high for all species showing that the protein is thermally stable. A higher instability index was observed in the CD14 molecule of rabbit, pig and monkey (53.0, 46.8 and 45.1 respectively), indicating that the protein is less stable and hydrophobic amino acids such as leucine, valine, serine and asparagine, occupy majority of the sequence, providing higher tolerance against diseases. The lowest instability index is observed in horse (33.5) and goat (35.1) showing that the protein is more stable in these species. The CD14 protein in goat also has the lowest aliphatic index (99.7) while mouse has the highest (107.7). We observed a closer range of molecular weight among the species in this study, although gorilla, monkey, human, chimpanzee and rat had the higher molecular weight with close range (Table 2). Negative net charge, indicative that the protein is more basic than acidic, ranged from -9 to as found in mouse and rat to +4 as found in goat. Goat, horse and gorilla has higher isoelectric point (Ip) indicating that CD14 molecule is highly basic in these species than others. The GRAVY values obtained were generally positive and higher in ruminants than non- ruminants suggesting the proteins are more hydrophobic, which enhances oligomerization and higher binding capability to different proteins. 
207

208

209

210

211

212

213

214

215

216

217

218

219

220

221

222

223

224

225

226

227

228

229

\section{Characterization of functional motifs and prediction of signal peptides}

The CD14 amino acid sequences of the 14 mammalian species in this study were individually scanned for matches against the InterPro and PROSITE collection of protein signature databases. We found one domain (Leucine-rich repeat (LRR), PS51450) with varying frequency across the 14 species (Figure 3). Comparison of the predicted intra-domain features show one LRR domain in human, two each in gorilla, chimpanzee, monkey, horse and pig, three each in cattle, sheep, buffalo, yak, and mouse, with the highest number (4) found in rat. Figure 4 shows the multiple sequence alignment of the homology of LRR domain across the 14 species, showing that leucine, aspartic acid, serine and asparagine are 100\% conserved in this region. The sequence logo built from the multiple sequence alignment of the domain is displayed in Figure 5, with the logo showing the relative frequencies of each conserved amino acid and their position in the LRR domain. The domain homology reveals that there is significant conservation of most amino acids in this region.

Furthermore, we predicted the signal peptides, position and secretory pathway of the CD14 amino acids in the 14 species under consideration. Our analysis shows that chimpanzee, gorilla, human and monkey share the same signal peptide (VSA-TT) at the same position (19 and 20), with high likelihood (Table 3). Buffalo, cattle, sheep and yak also share the same signal peptide (VSA-DT) and position (20 and 21) although sheep has a different position (19 and 20). We observed a significant variation for the rest of the species in terms of signal peptides and their positions (Table 3). Interestingly, signal peptide for all the species (Figure 6a), except sheep (Figure 6b), share the same subcellular localization in the neural networks. 


\section{Mutational analysis of predicted variation}

231 A total of 10 variants were selected from the predicted mutations by SIFT and the effects were

232 tested as deleterious or not in the 14 species with PROVEAN and PANTHER. Our analysis

233 showed that 4 of these variants (D28V, W45H, G62E, L70D) were validated mutations with

234 deleterious effect on all species with 2 others found in few species. These variants cluster in the

235 C-terminus region of CD14 protein between 20 to 100 amino acids. A closer look suggests that

236 mutational effect on the CD14 protein sequence varied from C-terminus to N-terminus with less

237 mutational effect towards the N-terminus (Table 4). The deleterious mutations observed in our

238 study were all at the C-terminus region thus identifying it as a mutational hotspot. Q100G,

239 V301M, L318I, G335T, L357H and G370K mutation spots were neutral for most species. This

240 might mean that CD14 is less conserved in this region because of evolutionary divergence of all

241 species. However, L-H at position 357 showed a deleterious effect in cattle, yak, pig, gorilla,

242 human, monkey, buffalo and chimpanzee, while there is also a deleterious effect of G-K at

243 position 370 of CD14 in rat.

\section{Protein-protein interaction cluster with CD14 gene in different species}

246 In order to deduce protein-protein interactions (PPI) that evolved through speciation due to co-

247 localization, additive genetic interaction, co-expression or repression and physical association

248 with CD14 in the mammalian species under study, we used STRING to build the protein network

249 based on collection of laboratory experimental results from the database (Figure 7) and segment

250 the gene pool base on our phylogenetic result to build Venn diagrams for each species cluster

251 (Figure 8a, b, c). We could not find any protein network for horse and so was excluded in the

252 analysis. Our result shows that there is significant variation in the CD14 protein interactome 
253 across species (Figure 7). Generally, we found that there were different proteins that clustered

254 with CD14 in all the species. All species had 10 proteins in their cluster except cattle and goat

255 that had 11. Looking at the Venn diagram, rabbit had the highest CD14 PPI that is not shared

256 with others while 3 protein set (CD14, TLR2 and TLR4) is common to members of this group

257 (Figure 8a). Figure 8b shows the ruminant group, including goat, sheep and yak had no unique

258 gene set, meaning the PPI is duplicated in one or two other members of the group. However,

259 cattle has 8 unique PPI while buffalo has 4 that were not shared with others. CD14 and TLR2 are

260 common to all in this group. Likewise, there were 8 unique PPI in human, 6 in gorilla and none

261 in monkey and chimpanzee (Figure 8c).

\section{Discussion}

264 Comparative analysis of CD14 protein in this study enhances our understanding of genome

265 plasticity among 14 mammalian species and establishes functional, molecular and structural

266 relationships in different clades that are important in an evolutionary trace. The significant

267 variability in the multiple sequence alignment of CD14 molecule across the species suggests a

268 high evolutionary divergence especially between the ruminant and non-ruminant group. This

269 implies that CD14 amino acid sequence had undergone significant changes during speciation

270 leading to functional and structural modification in different species. Studies have shown that

271 variation in amino acid sequences could impact immunogenicity, immunotolerance and

272 immunoreactivity (Tauber, 2004, Kanduc, 2012; Bendl et al., 2014). However, we found that

273 amino acid residues like leucine (L), glutamic acid (E), lysine (K), valine (V), aspartic acid (D),

274 glycine $(\mathrm{G})$, serine $(\mathrm{S})$ and asparagine $(\mathrm{N})$ are highly conserved, thereby retaining some degree

275 of homology in functional, molecular and structural characteristics. In addition, this reveals the 
276 common origin between the mammalian species before divergent speciation. Based on the

277 percentage identity and similarity, monkey, gorilla and chimpanzee are closer to human in their

278 CD14 amino acid sequence, suggesting a lower degree of variation and this may infer some

279 degree of similar CD14 expression during disease condition (Ferrero et al., 1990; Ibeagha-

280 Awemu et al., 2008; Bendl et al., 2014).

281

282 We also observed that the molecular weight, isoelectric point (Ip), instability index and net charge of CD14 protein for this group of mammals are similar, suggesting a key biochemical and immunological function is retained in these species during evolution (Saha et al., 2013; Ajayi et al., 2018). Of interest, the CD14 sequence in cattle and buffalo were much more conserved than yak, despite their common origin potentially implying that domestication has not affected key biological functions in cattle, and the possibility that buffalo can also be domesticated without loss of immunological function. Furthermore, a higher aliphatic index, net negative charge and GRAVY as shown in the physicochemical properties of CD14 protein in mouse and rat gives an indication of high concentration of alanine, valine, isoleucine and leucine, reported to influence transcription factors, providing higher tolerance against bacterial and viral infections (Korber, 2000; Panaro et al., 2008; Ivanov et al., 2015). This is thought to be an important evolutionary adaptation for these small animals to survive bouts of exposure to diseases in their environment, and may explain the basis for these organisms at times serving as reservoir hosts for many disease pathogens in humans. The general negative net charge of CD14 protein as observed across the species indicates an increasing reactivity and help in its receptor binding mechanism.

297 Therefore, the higher the net charge, the more the reactivity of the protein. 
299 Interestingly, our motif and signal peptide scan found just one domain and one signal peptide in

300 the entire length of CD14 amino acid sequence. The numbers of conserved leucine-rich repeat

301 (LRR) domains vary from species to species. Species with similar number of LRR profile may

302 likely have same immunological implications. This again, is a significant evolutionary signature.

303 CD14 is a co-receptor that bind with LPS, therefore a higher leucine amino acid profile in the

304 molecule may accelerate its binding mechanism to receptor in a significant way because the

305 protein plays a significant regulatory role in initiating a robust innate immune response. Studies

306 have shown that LRR domain is evolutionarily conserved in most of the innate immune related

307 proteins in vertebrates, invertebrates and plants, providing the innate immune defense especially

308 through pathogen-associated molecular patterns (PAMPs) (Aylwin and Ramnik 2011). Some

309 reports also stated that there about 2-45 leucine-rich repeats within the LRR domains, containing

310 up to 30 residues. Classifying our mammalian species under study into ruminants versus non-

311 ruminants, we observed that non-ruminants possess a lower number of LRR domain in their

312 CD14 molecule (one domain in human, three in ruminants and four in rat). Notably, rat again

313 possesses the highest number of LRR domains remarkably traceable to selection pressure across

314 the species. Moreover, the amino acid sequence of this domain is highly conserved for all species

315 under study, and are found towards the C-terminal region of CD14, justifying the fact that amino

316 acid sequence variation that differentiate species are found close to the N-terminal region (Peters

317 et al., 2018).

318

319 Our study additionally reveals varying secretory signal peptide sites in the CD14 molecule across

320 the species. Signal peptides have been identified as hydrophobic amino acids, recognized by the

321 signal recognition particle (SRP) in the cytosol of eukaryotic cells. Secretory signal peptide is a 
322 class of signal peptide that allows the export of a protein from the cytosol into the secretory

323 pathway (Nielsen and Krogh, 1998; Park and Kanehisa, 2003; Rivas and Fontanillo, 2010;

324 Sigrist et al., 2010). In this, we found that human, monkey, gorilla and chimpanzee all have the

325 same signal peptide site and position. Cattle, yak, sheep and buffalo also share the same site and

326 position whereas goat did not, confirming why goat is significantly distant to other ruminants in

327 our phylogenetic construction. It is unclear if this is related to disease tolerance when compared

328 to other species. However, we noted in our predicted neural network that the subcellular

329 localization of CD14 protein goes from the extracellular through the intracellular and enters the

330 secretory pathway for all the species, except sheep. In sheep, the subcellular localization begins

331 from the nucleus through the mitochondrion, peroxisomal targeting signal (PTS) and N-terminal

332 sequences before it enters into the secretory pathway. This information may possess potential

333 immunological consequences that will require further analysis and possibly an in-vitro

334 validation.

335

336

Of most importance, a higher proportion of the predicted mutations occupying the C-terminal region of CD14 protein show that they are closer to the active site and may have direct structural and functional effects on the protein thereby causing harmful disease phenotype or susceptibility (Malm and Nilssen, 2008). Studies have shown that the leucine-rich repeats at the C-terminal region is required for responses to smooth lipopolysaccharide, whereas the variable region (290 375) has been found to be necessary for response to bacterial lipopolysaccharide (Bella et al., 2008; Arnesen, 2011; Xue et al., 2012, 2018). Therefore, variation at this region might be traceable to varied exposure and responses to pathogens in the cause speciation. 
345 We observed a higher proportion of deleterious mutational spots in human, monkey, gorilla and

346 chimpanzee occupying the same loci compared to ruminants and other species. This might

347 suggest that the vital residue conservation at this region is due to selection pressure among these

348 species and has been maintained over time possibly because of their role in evolution, resulting

349 in similar biological and immunological function (Feder and Mitchell-Olds, 2003; De Donato et

350 al., 2017; Peters et al., 2018). Therefore, a perturbation of the amino acid sequence at this region

351 could affect the protein folding, ligand binding and other functions which might be lethal or

352 regarded as disease-causing mutation in all mammals. Understanding the molecular variation in

353 the region could help solve the challenge of Mendelian disease phenotypes. We recommend an

354 in vitro study of this region in CD14 protein sequence to elucidate the molecular mechanism

355 affecting functionality of this region. In all, 3 of these mutations have been characterized and

356 verified in humans to cause disruption of active site and loss of protein activities (Hidam and

357 Debasish, 2018).

358

359 Furthermore, we used the STRING database to annotate CD14 protein network with other

360 protein molecules that may have evolved together during speciation. Significantly, we found that

361 CD14 molecule selectively interact with other proteins from species to species. For example, in

362 cattle, CD14 molecule interacts with 8 other proteins, which are not shared with goat, sheep and

363 yak. In a similar vein, buffalo has 4 unique sets of protein that co-express with CD14 protein.

364 Human and gorilla in their group has 8 and 6 genes respectively that uniquely interact with CD14

365 protein, which are not found in monkey and chimpanzee. These protein interactions are possibly

366 due to the specific molecular or biochemical changes that occur in CD14 protein during selection

367 pressure in different species. This interactome is important to decipher molecular and 
368 biochemical mechanisms shaped by evolution, which may be useful for drug design and

369 therapeutic treatment of many diseases. Several studies have shown that molecular association

370 between chains of different protein molecules is geared by the electrostatic force like

371 hydrophobic effects which define specific bimolecular interaction in different organism (Arkin et

372 al., 2014; De Las and Fontanillo, 2010; Chen et al., 2013). The modulation of this interaction

373 may be useful as putative therapeutic targets for disease treatment in many species. Ivanov et al

374 (2013) have used the interaction of Tirobifan with glycoprotein IIb/IIIa as an inhibitor for

375 cardiovascular drug discovery, likewise the interaction of Maraviroc and CCR5-gp120 for anti-

376 HIV drug.

378 As shown earlier, there are variations in the number of the LRR domain among these species,

379 possibly the lesser number of LRR domain in human is supplemented or accounted for by the

380 functionality of other genes in the network (Thakur and Shankar, 2016). From our

381 physicochemical properties, CD14 is classified as hydrophobic across the species due to higher

382 proportion of LRR. The varying degree of LRR among these species is thought to affect the

383 electrostatic force created by the hydrophobic effects of the protein. Published studies have

384 shown that diverse fungal, bacterial, viral and parasite components are sensed by the mammalian

385 LRR domain of proteins like NOD-like receptors and Toll-like receptors (Korber, 2000; Kutay

386 and Guttinger, 2005; Lucchese et al., 2009; Kamaraj and Purohit 2014). Likewise, about 34

387 leucine-rich repeat proteins have been associated with diseases in human. Obviously, divergent

388 evolutionary events have shaped the protein-protein interaction of CD14 in different species,

389 which is thought to be significant to varying degrees of disease susceptibility and pathogen

390 selection. 


\section{Conclusion}

393 We have used computational methods to gather information on CD14 protein in 14 mammals.

394 Our in silico comparison of CD14 amino acid sequences among these species gave molecular

395 evidence of divergent evolutionary events that occurred during speciation, potentially of

396 significance in modulating innate immune response to pathogenic challenges. Obviously, this

397 gene has been subjected to selection pressure due to sufficient sequence variation we found from

398 one species to another. We identified mutational hotspots with damaging effects in human and

399 other species. In particular, the signal peptides located in these mutational hotspots are possibly

400 of major importance in immunological studies. The variants identified in this study can be

401 further subjected to validation through in vitro analysis. Since CD14 molecule is essential in

402 initiating proper immune response to pathogens and the precursor of a robust adaptive immune

403 response, our study highlights the effect of mutations on protein structure and disease outcome,

404 protein-protein interaction that may be essential for drug design, yielding themselves to

405 therapeutic manipulations for treating many diseases. Finally, these results contribute to our

406 understanding of the evolutionary mechanism that underlie species variation in response to

407 complex disease traits.

408

409

References

410

411

412

413
Ajayi OO, Peter SO, De Donato M, Mujibi FD, Khan WA, Hussain T, Babar ME, Imumorin IG, Thomas BN. 2018. Genetic variation in N- and C-terminal regions of bovine DNAJA1 heat shock protein gene in Africa, Asian and American cattle. Journal of Genomics. 6:1-8. doi: 10.7150/jgen.23248

Peer] reviewing PDF | (2019:04:36629:1:2:NEW 12 Jun 2019) 
414 Arkin MR, Tang Y, Wells JA. 2014. Small-molecule inhibitors of protein-protein interactions:

415 progressing towards the dream. Cell Chemical Biology 3:301-17.

416

DOI:10.1016/j.chembiol.2014.09.001

417

418

419

420

421

422

423

424

425

426

427

428

429

430

431

432

433

434

435

436

Arnesen, T. 2011. Towards a functional understanding of protein N-terminal acetylation. PLoS Biology, 9(5):e1001074. doi:10.1371/journal.pbio.100107

Bella J, Hindle KL, McEwan PA, Lovell SC. 2008. The leucine-rich repeat structure. Cell Molecular Life Science. 65: 2307-2333. 10.1007/s00018-008-8019-0

Bendl J, Stourac J, Salanda O, Pavelka A, Wieben ED, Zendulka J, Brezovsky J, Damborsky J. 2014. PredictSNP: Robust and Accurate Consensus Classifier for Prediction of Disease-Related Mutations. PLoS Computational Biology.10: e1003440. doi: 10.1371/journal.pcbi.1003440 PMID: 24453961

Bendl J, Stourac J, Salanda O, Pavelka A, Wieben ED, Zendulka J, Brezovsky J, Damborsky J. 2014. PredictSNP: robust and accurate consensus classifier for prediction of disease-related mutations. PLoS Computational Biology 10: e1003440.

Chen S, Krinsky BH, Long M. 2013. New genes as drivers of phenotypic evolution. Nature Reviews Genetics. 14:645-60. doi: 10.1038/nrg3521.

Choi Y, Chan AP. 2015. PROVEAN web server: a tool to predict the functional effect of amino acid substitutions and indels. Bioinformatics 31:2745-7.

Choi Y, Sims GE, Murphy S, Miller JR, Chan AP. 2012. Predicting the Functional Effect of Amino Acid Substitutions and Indels. PLoS ONE. 7: e46688. doi: 10.1371/journal.pone.0046688 PMID: 23056405

De Donato M, Peters SO, Hussain T, Rodulfo H, Thomas BN, Babar ME, Imumorin IG. 2017. Molecular evolution of type II MAGE genes from ancestral MAGED2 gene and 

54.

439

440

441

442

443

444

445

446

447

448

449

450

451

452

453

454

455

456

457

458

459

Dultz E, Hildenbeute M, Martoglio B. Hochman J, Dobberstein B, Kapp K. 2008. The signal peptide of the mouse mammary tumor virus Rem protein is released from the endoplasmic reticulum membrane and accumulates in nucleoli. Journal of Biological Chemistry. 283:9966-76. DOI:10.1074/jbc.M705712200

Feder ME, Mitchell-Olds T. 2003. Evolutionary and ecological functional genomics. Nature Reviews Genetics 4:651-7. DOI:10.1038/nrg1128

Ferrero E, Hsieh C L, Francke U, Goyert SM. 1990. CD14 is a member of the family of leucine-rich proteins and is encoded by a gene syntenic with multiple receptor genes. Journal of Immunology 145:331-336

Härtel C, Rupp J, Hoegemann A, Bohler A, Spiegler J, von Otte S, Röder K, Schultz C, Göpel, W. 2008. 159C > T CD14 genotype-functional effects on innate immune responses in term neonates. Human Immunology 69: 338-343

Hepp D, Gonçalves GL, de Freitas TR. 2015. Prediction of the Damage-Associated NonSynonymous Single Nucleotide Polymorphisms in the Human MC1R Gene. PLoS ONE 10: e0121812. doi:10.1371/journal.pone.0121812

Hidam B and Debasish B. In silico assessment of human CD14 gene revealed high-risk single nucleotide polymorphisms and their impact on innate immune response against microbial pathogens. Meta Gene 2018;17. DOI: 10.1016/j.mgene.2018.05.010

Huyen Y, Jeffrey PD, Derry WB, Rothman JH, Pavletich NP, Stavridi ES, Halazonetis TD. 2004. Structural differences in the DNA binding domains of human p53 and its C. elegans ortholog Cep-1. Structure.12:1237-1243. 
460 Ibeagha-Awemu EM, Lee JW, Ibeagha AE, Zhao X. 2008. Bovine CD14 gene

461

462

463

464

465

466

467

468

469

470

471

472

473

474

475

476

477

478

479

480

characterization and relationship between polymorphisms and surface expression on monocytes and polymorphonuclear neutrophils. BMC Genetics 9:50.

Ivanov SM, Lagunin AA, Pogodin PV, Filimonov DA, Poroikov VV. 2014. Identification of drug-induced myocardial infarction-related protein targets through the prediction of drug-target interactions and analysis of biological processes. Chemical Research in Toxicology 27: 1263-1281.

Ivanov SM, Lagunin AA, Pogodin PV, Filimonov DA, Poroikov VV. 2015. Identification of drug targets related to the induction of ventricular tachyarrhythmia through a systems chemical biology approach. Toxicological Sciences 145: 321-336. doi: 10.1093/toxsci/kfv054

Käll L, Krogh A, Sonnhammer EL. 2004. A combined transmembrane topology and signal peptide prediction method. Journal of Molecular Biology 338:1027-1036.

Kamaraj B, Purohit R. 2013. In silico screening and molecular dynamics simulation of diseaseassociated nsSNP in TYRP1 gene and its structural consequences in OCA3. Biomedical Research International 697051. doi: 10.1155/2013/697051 PMID: 23862152

Kamaraj B, Purohit R. 2014. Computational Screening of Disease-Associated Mutations in OCA2 Gene. Cell Biochemistry and Biophysics. 68: 97-109. doi: 10.1007/s12013-0139697-2 PMID: 23824587

Kanduc D. 2012. Homology, similarity, and identity in peptide epitope immunodefinition. Journal of Peptide Science 18: 487-494. DOI 10.1002/psc.2419

Peer] reviewing PDF | (2019:04:36629:1:2:NEW 12 Jun 2019) 
481

482

483

484

485

486

487

488

489

490

491

492

493

494

495

496

497

498

499

500

501

502

Khan JM, Ranganathan S. 2009. A multi-species comparative structural bioinformatics analysis of inherited mutations in a-D-Mannosidase reveals strong genotype-phenotype correlation. BMC Genomics 10:S33 doi: 10.1186/1471-2164-10-S3-S33

Korber B. 2000. HIV signature and sequence variation analysis. In: Rodrigo Allen G, Learn Gerald H., editors. Computational Analysis of HIV Molecular Sequences. Chapter 4. Dordrecht, Netherlands: Kluwer Academic Publishers; pp. 55-72.

Kutay U, Guttinger S.2005. Leucine-rich nuclear-export signals: born to be weak. Trends Cell Biology 15:121-4

\section{Liu H-H, Hu Y, Zheng M, Suhoski MM, Engleman EG, Dill DL, Hudnall M, Wang J,} Spolski R, Leonard WJ, Peltz G. 2012. Cd14 SNPs regulate the innate immune response. Molecular Immunology, 51:112-127

Lucchese A, Serpico R, Crincoli V, Shoenfeld Y, Kanduc D. 2009. Sequence uniqueness as a molecular signature of HIV-1-derived B-cell epitopes. International Journal of Immunopathology and Pharmacology 22: 639-646.

Malm D, Nilssen Ø. 2008. Alpha-mannosidosis. Orphanet Journal of Rare Disease. 23:21. doi: $10.1186 / 1750-1172-3-21$.

Meng QJ, Master AM, Beesley S, Lu WQ, Gibbs J, Parks D, Collins J, Farrow S, Donn R, Ray D, Loudon A. 2008. Ligand modulation of REV-ERB $\alpha$ function resets the peripheral circadian clock in a phasic manner. Journal of Cell Sciences 121: 3629-3635; doi: $10.1242 /$ jcs. 035048

Meng X, Noyes MB, Zhu LJ, Lawson ND, Wolfe SA. 2008. Targeted gene inactivation in zebrafish using engineered zinc-finger nucleases. Nature Biotechnology 26:695-701. 
503

504

505

506

507

508

509

510

511

512

513

514

515

516

517

518

519

520

521

522

523

524

525

Morisseau C, Wecksler AT, Deng C, Dong H, Yang J, Lee KSS, Kodani SD, Hammock BD.

2014. Effect of soluble epoxide hydrolase polymorphism on substrate and inhibitor selectivity and dimer formation. The Journal of Lipid Research. 55: 1131-1138. doi: 10.1194/jlr.M049718.

Ng A, Xavier RJ. 2011. Leucine-rich repeat (LRR) proteins: Integrators of pattern recognition and signaling in immunity. Autophagy 7: 9. https://doi.org/10.4161/auto.7.9.16464

Ng PC, Henikoff S. 2006. Predicting the effects of amino acid substitutions on protein function. Annu Rev Genomics Human Genetics. 7:61-80.

DOI:10.1146/annurev.genom.7.080505.115630

Nielsen H, Krogh A. 1998. Prediction of signal peptides and signal anchors by a hidden Markov model. Proc. Int. Conf. Intell. Syst. Molecular Biology 6:122-130

Oakley MS, Majam V, Mahajan B, Gerald N, Anantharaman V, Ward JM, Faucette LJ, McCutchan TF, Zheng H, Terabe M, Berzofsky JA, Aravind L, Kumar S. 2009. Pathogenic roles of CD14, galectin-3 and OX40 during experimental cerebral malaria in mice. PLoS ONE, 4(8):e6793

Ojurongbe O, Funwei RI, Snyder T, Aziz N, Li Y, Falade C, Thomas BN. 2017. Genetic diversity of CD14 promoter gene polymorphism (rs2569190) is associated with regulation of parasitemia but not susceptibility to Plasmodium falciparum infection. Infectious Diseases: Research and Treatment, 10:1-6. doi: 10.1177/1178633617726781.

Panaro MA, Cianciulli A, Gagliardi N, Mitolo CI, Acquafredda A, Cavallo P, Mitolo V. 2008. CD14 major role during lipopolysaccharide-induced inflammation in chick embryo cardiomyocytes, FEMS Immunology \& Medical Microbiology, 53:35-45. $\underline{\text { https://doi.org/10.1111/j.1574-695X.2008.00397.x }}$ 
526 Park KJ, Kanehisa M. 2003. Prediction of protein subcellular locations by support vector

527

528

529

530

531

532

533

534

535

536

537

538

539

540

541

542

543

544

545

546

547

548

machines using compositions of amino acids and amino acid pairs. Bioinformatics

19:1656-1663.

Peters SO, De Donato M, Hussain T, Rodulfo H, Babar ME and Imumorin IG. 2018.

Sequence variation of necdin gene in Bovidae. Journal of Animal Science and

Technology 60:32. https://doi.org/10.1186/s40781-018-0191-7

Reiling N, Hölscher C, Fehrenbach A, Kröger S, Kirschning CJ, Goyert S, Ehlers S. 2002. Cutting edge: Toll-like receptor (TLR)2- and TLR4-mediated pathogen recognition in resistance to airborne infection with Mycobacterium tuberculosis. Journal of Immunology 169:3480-3484

Rivas JL, Fontanillo C. 2010. Protein-Protein Interactions Essentials: Key Concepts to Building and Analyzing Interactome Networks. PLoS Computational Biology. https://doi.org/10.1371/journal.pcbi.1000807

Saha R, Saha N, Donofrio RS, Bestervelt LL. 2013. Microbial siderophores: a mini review. Journal of Basic Microbiology. 53: 303-317. https://doi.org/10.1002/jobm.201100552

Sigrist CJA, Cerutti L, de Castro E, Langendijk-Genevaux PS, Bulliard V, Bairoch A, Hulo N 2010. PROSITE, a protein domain database for functional characterization and annotation. Nucleic Acids Research 38(Database issue):D161-D166

Song Y, Sun L, Guo A, Yang L. 2014. Toll-like receptor 6 gene polymorphisms increase the risk of bovine tuberculosis in Chinese Holstein cattle. Acta Histochemistry. 116:1159-62. doi: 10.1016/j.acthis.2014.06.004.

Sugawara S, Yang S, Iki K, Hatakeyama J, Tamai R, Takeuchi O, Akashi S, Espevik T, Akira S, Takada H. 2001. Monocytic cell activation by Nonendotoxic glycoprotein 
from Prevotella intermedia ATCC 25611 is mediated by toll-like receptor 2. Infectious

550 Immunology 69:4951-4957. DOI: 10.1128/IAI.69.8.4951-4957.2001

551

552

553

554

555

556

557

558

559

560

561

562

563

564

565

566

567

568

569

570

Tamura K, Stecher G, Peterson D, Filipski A, Kumar S. 2013. MEGA6: molecular evolutionary genetics analysis version 6.0. Molecular Biology Evolution 30:2725-2729

Tang AT, Choi JP, Kotzin JJ, Yang Y, Hong CC, Hobson N, Girard R, Zeineddine HA, Lightle R, Moore T, Cao Y, Shenkar R, Chen M, Mericko P, Yang J, Li L, Tanes C, Kobuley D, Võsa U, Whitehead KJ, Li DY, Franke L, Hart B, Schwaninger M, Henao-Mejia J, Morrison L, Kim H, Awad IA, Zheng X, Kahn ML. 2017. Endothelial TLR4 and the microbiome drive cerebral cavernous malformations. Nature. 18; 545(7654): 305-310. doi: 10.1038/nature22075

Tauber E, Last KS, Olive PJ, Kyriacou CP. 2004. Clock gene evolution and functional divergence. Journal of Biological Rhythms, 19:445- 458.

Tauber E, Zordan M, Sandrelli F, Pegoraro M, Osterwalder N, Breda C, Daga A, Selmin A, Monger K, Benna C, Rosato E, Kyriacou CP and Costa R. 2007. Natural selection favors a newly derived timeless allele in Drosophila melanogaster. Science 316: 18951898.

Thakur R and Shankar J. 2016. In silico analysis revealed high-risk single nucleotide polymorphisms in human pentraxin-3 gene and their impact on innate immune response against microbial pathogens. Frontiers in Microbiology 7:192. doi: 10.3389/fmicb.2016.00192

Thomas BN, Donvito B, Cockburn I, Fandeur T, Rowe JA, Cohen JHM, Moulds JM. 2005. A complement receptor-1 polymorphism with high frequency in malaria endemic 
regions of Asia but not Africa. Genes and Immunity. 6:31-36. doi:

572 $10.1038 /$ sj.gene. 6364150

573

574

575

576

577

578

579

580

581

582

583

584

585

586

587

588

589

590

591

592

Valastyan JS, Lindquist S. 2014. Mechanisms of protein-folding diseases at a glance. Disease Model and Mechanism. 7:9-14. doi: 10.1242/dmm.013474.

Viriyakosol S, Kirkland TN. 1996. The N-terminal half of membrane CD14 is a functional cellular lipopolysaccharide receptor. Infection and immunity 64:653-656.

Xue Y, Gao WN, Chen F, Ma BB, Zhou F, Hu ZG, Long T, Zhao ZQ. 2018. CD14 gene polymorphisms associated with increased risk of bovine tuberculosis in Chinese Holstein cows. The Veterinary Journal 232:1-5. doi: 10.1016/j.tvj1.2017.11.015

Xue Y, Zhao ZQ, Chen F, Zhang L, Li GD, Ma KW, Bai XF, Zuo YJ. 2012. Polymorphisms in the promoter of the CD14 gene and their associations with susceptibility to pulmonary tuberculosis. Tissue Antigens 80: 437-443.

Yue P, Moult J. 2005. Identification and analysis of deleterious human SNPs. Journal of Molecular Biology. 10:1263-74. DOI:10.1016/j.jmb.2005.12.025

Zanoni I, Granucci F. 2013. Role of CD14 in host protection against infections and in metabolism regulation. Frontiers in Cellular and Infection Microbiology 3:1-6

Zeron-Medina J, Wang X, Repapi E, Campbell MR, Su D, Castro-Giner F, Davies B, Peterse EF, Sacilotto N, Walker GJ, Terzian T, Tomlinson IP, Box NF, Meinshausen N, De Val S, Bell DA, Bond GL. 2013. A polymorphic p53 response element in KIT ligand influences cancer risk and has undergone natural selection. Cell. 10:410-22. doi:10.1016/j.cell.2013.09.017 


\section{Table 1 (on next page)}

Percentage identity (similarity) of the CD14 protein across mammalian species 


\section{Table 1: Percentage identity (similarity) of the CD14 protein across the selected mammalian species}

\begin{tabular}{|c|c|c|c|c|c|c|c|c|c|c|c|c|c|c|}
\hline Human & $100(100)$ & & & & & & & & & & & & & \\
\hline Rat & $23.1(27.9)$ & $100(100)$ & & & & & & & & & & & & \\
\hline Mouse & $10.4(14.5)$ & 7.4 (13.4) & $100(100)$ & & & & & & & & & & & \\
\hline Cattle & $8.3(11.5)$ & $10.2(15.1)$ & $10.9(15.3)$ & $100(100)$ & & & & & & & & & & \\
\hline Rabbit & $29.3(33.6)$ & $15.6(21.5)$ & $9.3(15.0)$ & $9.4(13.4)$ & $100(100)$ & & & & & & & & & \\
\hline Goat & $6.7(9.9)$ & $9.9(15.1)$ & 9.7 (13.7) & $87.4(89.3)$ & $10.2(14.2)$ & $100(100)$ & & & & & & & & \\
\hline Monkey & $95.2(96.3)$ & $23.1(28.0)$ & $10.7(14.5)$ & $8.6(12.1)$ & $29.0(33.9)$ & $6.9(10.5)$ & $100(100)$ & & & & & & & \\
\hline Gorilla & $99.2(99.5)$ & $23.1(28.0)$ & $10.4(14.2)$ & $8.3(11.5)$ & $29.0(33.6)$ & $6.7(9.9)$ & $95.5(96.3)$ & $100(100)$ & & & & & & \\
\hline Sheep & $20.8(26.4)$ & $12.4(17.0)$ & 7.9 (13.9) & $8.9(10.5)$ & $19.4(25.3)$ & $8.6(10.8)$ & $21.3(27.0)$ & $21.0(26.4)$ & $100(100)$ & & & & & \\
\hline Horse & $6.9(13.2)$ & $11.3(17.1)$ & $7.7(13.8)$ & $8.8(13.8)$ & $8.3(14.0)$ & $8.8(13.5)$ & $6.6(12.9)$ & 6.9 (11.8) & $6.9(11.8)$ & $100(100)$ & & & & \\
\hline Pig & $18.5(23.3)$ & $13.2(19.1)$ & $10.9(14.5)$ & $67.6(71.6)$ & $18.8(23.1)$ & $60.1(64.9)$ & $19.3(23.6)$ & $18.8(23.3)$ & $19.1(22.9)$ & $8.0(13.2)$ & $100(100)$ & & & \\
\hline Buffalo & $8.0(11.3)$ & $9.9(14.8)$ & $10.7(15.3)$ & $96.5(97.3)$ & $9.4(13.2)$ & $86.1(88.7)$ & $8.3(11.8)$ & $8.0(11.3)$ & $8.9(10.8)$ & $8.5(12.9)$ & $66.8(71.3)$ & $100(100)$ & & \\
\hline Chimp & $98.9(99.2)$ & $23.1(28.2)$ & $10.9(14.8)$ & $8.6(11.8)$ & $29.0(33.6)$ & $6.9(10.2)$ & $95.2(96.0)$ & $99.2(99.2)$ & $21.0(26.7)$ & $6.9(13.2)$ & $19.0(23.6)$ & $8.3(11.5)$ & $100(100)$ & \\
\hline \multirow[t]{2}{*}{ Yak } & $8.3(12.0)$ & $8.6(14.2)$ & $9.0(12.3)$ & $42.1(45.3)$ & $8.3(14.0)$ & $37.5(42.1)$ & $8.3(12.3)$ & $8.3(12.0)$ & $9.4(13.2)$ & $8.0(14.0)$ & $21.4(26.5)$ & $41.0(44.5)$ & $8.5(12.3)$ & $\begin{array}{c}100 \\
(100)\end{array}$ \\
\hline & Human & Rat & Mouse & Cattle & Rabbit & Goat & Monkey & Gorilla & Sheep & Horse & Pig & Buffalo & Chimp & Yak \\
\hline
\end{tabular}

SB̊nilarity: Minimum $=9.91 ;$ Maximum $=100 ;$ Mean $=32.58 ;$ Standard deviation $=30.99$ 
Table 2 (on next page)

Physicochemical properties of the CD14 promoter region in selected mammalian species 
Table 2: Physicochemical properties of the CD14 molecule across the selected mammalian species

\begin{tabular}{|c|c|c|c|c|c|c|c|}
\hline Species & Amino acids size & $\begin{array}{c}\text { Molecular weight } \\
\text { (Da) }\end{array}$ & $\begin{array}{c}\text { Isoelectric } \\
\text { point }\end{array}$ & $\begin{array}{l}\text { Instability } \\
\text { index }\end{array}$ & $\begin{array}{l}\text { Aliphatic } \\
\text { index }\end{array}$ & Net charge & GRAVY \\
\hline Chimpanzee & 375 & 40135.34 & 5.92 & 43.44 & 104.61 & -4 & 0.113 \\
\hline Gorilla & 375 & 40005.15 & 6.10 & 42.27 & 102.80 & -3 & 0.094 \\
\hline Human & 375 & 40076.20 & 5.84 & 42.93 & 101.76 & -5 & 0.083 \\
\hline Monkey & 375 & 40127.19 & 5.69 & 45.10 & 102.80 & -6 & 0.085 \\
\hline Horse & 363 & 38450.27 & 6.19 & 33.47 & 103.06 & -3 & 0.096 \\
\hline Mouse & 366 & 39203.94 & 5.08 & 41.16 & 107.70 & -9 & 0.051 \\
\hline Pig & 373 & 39724.01 & 5.82 & 46.83 & 103.40 & -4 & 0.073 \\
\hline Rabbit & 372 & 39992.29 & 5.72 & 52.99 & 103.33 & -5 & 0.041 \\
\hline Rat & 372 & 40053.85 & 5.33 & 40.19 & 104.11 & -9 & 0.033 \\
\hline Buffalo & 373 & 39756.09 & 5.84 & 41.49 & 101.80 & -2 & 0.099 \\
\hline Cattle & 373 & 39666.79 & 5.37 & 41.70 & 102.06 & -5 & 0.099 \\
\hline Goat & 373 & 39930.28 & 8.47 & 35.07 & 99.71 & +4 & 0.032 \\
\hline Sheep & 371 & 39368.43 & 5.50 & 40.27 & 101.54 & -5 & 0.087 \\
\hline Yak & 381 & 40481.75 & 5.54 & 41.63 & 102.23 & -4 & 0.082 \\
\hline
\end{tabular}




\section{Table 3(on next page)}

Prediction of signal peptides and properties of the CD14 molecule in selected mammalian species 
Table 3: Prediction of signal peptides and properties of the CD14 molecule in selected mammalian species

\begin{tabular}{|c|c|c|c|c|c|c|}
\hline Species & Amino acids size & Cleavage position & Signal site & Probability & Likelihood & Others \\
\hline Chimpanzee & 375 & 19 and 20 & VSA-TT & 0.9140 & 0.9991 & 0.0009 \\
\hline Gorilla & 375 & 19 and 20 & VSA-TT & 0.9077 & 0.9991 & 0.0009 \\
\hline Human & 375 & 19 and 20 & VSA-TT & 0.9142 & 0.9991 & 0.0009 \\
\hline Monkey & 375 & 19 and 20 & VSA-TT & 0.9142 & 0.9991 & 0.0009 \\
\hline Horse & 363 & 14 and 15 & AAT-LE & 0.2069 & 0.675 & 0.3250 \\
\hline Mouse & 366 & 17 and 18 & ASP-AP & 0.4563 & 0.9991 & 0.0009 \\
\hline Pig & 373 & 19 and 20 & VSA-AT & 0.7699 & 0.9989 & 0.0011 \\
\hline Rabbit & 372 & 19 and 20 & AST-DT & 0.6574 & 0.9981 & 0.0019 \\
\hline Rat & 372 & 17 and 18 & VHA-SP & 0.8795 & 0.9998 & 0.0002 \\
\hline Buffalo & 373 & 20 and 21 & VSA-DT & 0.9712 & 0.999 & 0.0010 \\
\hline Cattle & 373 & 20 and 21 & VSA-DT & 0.9750 & 0.9992 & 0.0008 \\
\hline Goat & 373 & 20 and 21 & VTA-DK & 0.9642 & 0.9991 & 0.0009 \\
\hline Sheep & 371 & 19 and 20 & VSA-DT & 0.9000 & 0.9453 & 0.0547 \\
\hline Yak & 381 & 20 and 21 & VSA-DT & 0.9752 & 0.9993 & 0.0007 \\
\hline
\end{tabular}




\section{Table 4(on next page)}

Prediction of amino acid mutation at the mutational hotspot of CD14 molecule in selected mammalian species 
1 Table 4 Prediction of amino acid consequence at the mutational hotspot of CD14 molecules in selected mammalian species

\begin{tabular}{|c|c|c|c|c|c|c|c|c|c|c|}
\hline Species & D28V & W45H & G62E & L70D & Q100G & V301M & L318I & G335T & L357H & G370K \\
\hline Chimpanzee & -3.472 & -4.705 & -3.154 & -3.083 & -2.591 & -1.905 & -1.378 & -1.397 & -3.088 & -2.287 \\
\hline Gorilla & -3.822 & -4.651 & -3.216 & -2.984 & -2.554 & -2.049 & -1.446 & -1.397 & -3.050 & -2.285 \\
\hline Human & -3.679 & -4.680 & -3.008 & -3.056 & -2.756 & -2.043 & -1.445 & -1.395 & -3.229 & -2.305 \\
\hline Monkey & -3.563 & -4.782 & -3.238 & -3.038 & -2.758 & -1.933 & -1.444 & -1.293 & -3.089 & -2.268 \\
\hline Horse & -3.742 & -4.914 & -3.513 & -3.524 & -2.364 & -1.896 & -1.412 & -0.983 & -2.054 & -2.067 \\
\hline Mouse & -3.437 & -4.803 & -3.408 & -1.635 & -2.754 & -2.009 & -1.408 & -1.534 & -2.437 & -1.828 \\
\hline Pig & -3.712 & -5.054 & -3.702 & -1.873 & -2.329 & -2.013 & -1.637 & -1.235 & -2.902 & -2.052 \\
\hline Rabbit & -2.759 & -4.293 & -2.910 & -4.007 & -2.744 & -1.969 & -1.574 & -0.544 & -1.865 & -2.451 \\
\hline Rat & -3.478 & -4.725 & -3.373 & -1.058 & -2.905 & -2.038 & -1.351 & 0.464 & -2.497 & -2.619 \\
\hline Buffalo & -3.310 & -5.083 & -3.497 & -3.130 & -2.169 & -2.064 & -1.390 & -1.427 & -3.065 & -2.213 \\
\hline Cattle & -3.289 & -5.038 & -2.998 & -2.991 & -2.095 & -2.131 & -1.385 & -1.758 & -2.634 & -2.191 \\
\hline Goat & -3.919 & -4.906 & -3.964 & -3.390 & -2.461 & -2.046 & -1.476 & -0.631 & -1.439 & -1.601 \\
\hline Sheep & -3.559 & -4.952 & -4.072 & -3.206 & -2.312 & -1.981 & -1.246 & -1.376 & -2.335 & -1.695 \\
\hline Yak & -3.229 & -5.036 & -3.081 & -3.188 & -2.233 & -2.097 & -1.385 & -1.575 & -2.668 & -2.225 \\
\hline
\end{tabular}

2 Prediction (cutoff $=-2.5$ ); values above cutoff are considered deleterious; values below cutoff are considered neutral 


\section{Multiple sequence alignment of CD14 promoter regions between mammalian species}

1

HOMAN MERASCLLLL LL?-LVHVSA TTPEPCELDD ED--FRCVCN FSEPQPDWSE AFQCVSAVEV EIHAGGLNLE PFLKRVDADA DPRQYADTVK ALRVRRLTVG AAQVPAQLLV GALRVLAYSR LKELTLEDLK GORILLA MGRASCLLLL LL?-LVHVSA TTPEPCELDD ED--FRCVCN FSEPQPDWSE AFQCVSAVEV EIRAGGLNLE PFLKRVDADA DPRQYADTVK ALRVRRLTVG AAQVPAQLLV GALRVLAYSR LKELTLEDLK

CHIMPANZEE MERASCLLLL LLP-LVHVSA TTPEPCELDD ED--FRCVCN FSEPQPDWSE AFQCVSAVEV EIRAGGLNLE PFLKRVDADA DLRQYADTVK ALRVRRLTVG AAQVPAQILV VALRVLAYSR LKELTLEDLK MONKEY MERASCLLLL LL?-LVHVSA TTPEPCELDD ED--FRCVCN FSEPHPDWSE AFQCVSAVEV EIRVGGLSLE PFLTRVDPDA DPRQYADTIK ALRVRRLTVG AAQVPAQLLV GALRVLAYSR LQELTLEDLE RABBIT MEPVPCLLLL LL?-LLRAST DTPEPCELDD DD--IRCVCN FSDPQPDWSS ALQCMPAVQV EMNGGGHSLE QELRQADLYT DQRRYADVVK ALRVRRLTVG AVQVPAPILL GVLRVLGYSR LKELALEDIB

HORSE LLL LL?-LLRFSA ATLEPCEVDD EN--FRCVCN FTGPQPDWSS AFQCMTAVEV EIRGGGRNLE QFLKGAS--A DPRQYADIVK ALRLQRLTVG AVQVPAPLLV ALLRALGYSR LKELTLEDLE BOVINE MVCVPYLLLL LL?SLLRVSA DTTEPCELDD DD--FRCVCN FTDPKPDWSS AVQCMVAVEV EISAGGRSLE QFL-R-GADT NPRQYADTIK ALRVRRLKLG AAQVPAQLLV AVLRALGYSR LKELTLEDLE

YAK QVCVPYLLLL LL?SLLRVSA DTTEPCELDD DD--FRCVCN FTDPRPDWSS AVQCMVAVEV EISAGGRSLE QEL-K-GADT NPRQYADTIK ALRVRRLKLG AAQVPAQILV AVLRALGYSR LKELTLEDLE

BUFFALO MVCVPYLLLL LL?PLLRVSA DTTEPCELDD DD--FRCVCN FTDPKPDWSS AVQCMVAVEV EISGGGRSLE QEL-R-GADT NPRQYADTIK ALRVRRLKLG AAQVPAQILV AVLRALGYSR LKELTLEDLE

SHEEP VCVPSLLLL LP?PLLLRVSA DTTEPCELDD DD--FRCVCN FTDPKPDWSS AVQCMVAVEV EIRGGGHSLD QFL-K-GVNT DPRQYADTIK ALRVRRLKLG AAQVPAQILV AVLRALGYSR LKELTLEDLE

GOAT MVCVPYLLLL LLSALLRVTA DKREPCELDP QH--FRCVCN FTDPKPDWSS AVQCMVAVEV EIRGGGHSLD QEL-K-GANT DPKQYADTIK ALRVRRLKLG AAQVPAQILV AVLRALGYSR LKELTTLEDLE

PIG MVRLPCPLLL LL?-LLRVSA ATPEPCQIDD ED--VRCVCN FTHPQPDWSS ALQCVAAVEV EIRGGGRSLD EFLLK-SASA NPKQYADMLK ALRLRRLTVG AARVPAQILA LVLHALGFSR LKELTLEDLB

RAT MKLMLGLLL LPLTLVHASP ATPEPCELDQ DEESVRCYCN FSDPQPNWSS AFLCAGAEDV EFYGGGRSLE YLLKRVDTEA NLGQYTDIIR SLPLKRLTVR SARVPTQILF GTLRVLGYSG LRELTLENLB

MOUSE MERVLGLLL L--LLVHASP APPEPCELDE ES----CSCN FSDPKPDWSS AFNCLGAADV ELYGGGRSLE YLLKRVDTEA DLGQETDIIK SLSLKRLTVR AARIPSRILF GALRVLGISG LQELTLENLE

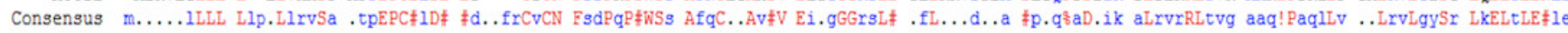

131

HOMAN ITGTMPPLP- LEA------- -TGLALSSLR LRNVSWATGR SWLAELQQWL KPGLKVLSIA QAHSPAFSCE QVRAFPALTS LDLSDNPGLG ERGLMAALCP HKFPAIQNLA LRNTGMETPT GVCAALAAAG GORILLA ITGTMPPLP- LEA------ -TGLALSSLR LRNVSWATGR SWLAELQQWL KPGLKVLSIA QAHSPAFSCE QVRAFPALTS LDLSDNPGLG ERGLIAALCP HKEPAIQNLA LRNTGMETPT GVCAALAAAAG CHIMPANZEE ITGTMPPLP- LEA------- -TGLALSSLR LRNVSWATGR SWLAELQQWL KPGLKVLSIA QAHSPAFSCE QVRAFPALTS LDLSDNPGLG ERGLIAALCP HKFPAIQNLA LRNTGMETPT GVCAALAAAG MONKEY ITGTMPPLP- LEג------- -TGLALSSLR LHNVSWATGR SNLAELQQWL KPGLKVLSIA QAHSPAFSCE QVRAFPALTS LDLSDNPGLG ERGLIAALCP HKFPALQNLA LRNTGMETPT GVCAALAAAG RABBIT VTGTAPPPPP LEA------ -TGPALSTLS LRNVSWPKGG ANLSELQQWL KPGLQVLNIA QAHTLAFSCE QVRTFSALTT LDLSENPGLG ERGLVAALCP HKFPALQLLA LRNAGMKTLQ GVCAALAEAG HORSE VTGTMQPPP- LEA------ -TGPPLSSLR LRNVSWATGG ANLAELQQWL KPGLKILSIA QAHSLAFSCA QLHSFSALHT LDLSDNPGLG ERGLIAALCP HKFPALRDLA LRNAGMQTPN GVCAAMAAAGG BOVINE VTGPTPPTP- LEA------ -AGPALTTLS LRNVSWTTGG AWLGELQQWL KPGLRVLNIA QAHSLAFPCA GLSTFEALTT LDLSDNPSLG DSGLMAALCP NKEPALQYLA LRNAGMETPS GVCAALAAAR

YAK VIGPTPPTP- LEATPPPLLK AAGPALTTLS LRNVSWTTGG AWLGELQQWL KPGLRVLNIA QAHSLAFPCA GLSTFEALTT LDLSDNPSLG DSGLMAALCP NKFPALQYLA LRNAGMETPS GVCAALAAAR

BUFFALO VIGPMPPKP- LEA------ -TGPAFTTLS LRNVSWATGG ANLGELQQWL KPGLRVLNIA QAHSLAFPCA GLSTFEALTT LDLSDNPSLG DTGLMAALCP NKFPALQCLA LRNAGMDKLS GVCAALAAAR

SHEEP VTGPTPPTP- LEA------ -TGPALTTLS LRNVSWATGG AWLGELQQWL KPGLRALNIA QAHSLAFPCA GLSTFEALTT LDLSDNPSLG DSGLMAALCP NKFPALQYLA LRNAGMETPS GVCAALAAAR

GOAT VTGPTPPAP- LEA------ -TGPALTTLS LRNVSGTTGG ANLGELQPWL KPGLRALNIA QAHSLAFPCA GLSTFEALTT LDLSDNPSLG DSGLMAALCP NKFRAPQYLA LRNAGMEAAT RPCAPLAAAR

PIG VTGQVPPPL- QET------ - -PGPALTTLR LRNVSWATGG ANLGELQQWL QPSLKVIKVA QASSLAFPCA QLRAFPALTT LDLSDNPGLG ERGLTAALCP RKFPALEDLA LRNAGVETPS GVCAALAGAG

RAT VTGTALSPL- LDA------- -TGPDLNTLS LRNVSWATTD TWLAELQQWL KPGLKVLSIA QAHSLNFSCK QVGVFPALAT LDLSDNPELG EKGLISALCP HKEPTLQVLA LRNAGMETTS GVCSALAAAR

MOUSE VTGTAPPPL- LEA------ -TGPDLNILN LRNVSWATRD ANLAELQQWL KPGLKVLSIA QAHSLNFSCE QVRVFPALST LDLSDNPELG ERGLISALCP LKFPTLQVLA LRNAGMETPS GVCSALAAAR

Consensus !TGt.pppp. 1ła tGpaL.tL. LRNVSWatgg aWLaELQQWL kPgLkvLs!A QAhslaFsC. qvr.FpALtt LDLS\$NPgLG ¥rGL.aALCP hKFPalq.LA LRNaGmetps GVCaA\$̣AaAg

261

HOMAN VQPHSLDLSH NS-RATVNPS APRCMNSAL NSLNLSEAGL FQVPKGLPAK LRVLDLSCNR LNRAPQPDEL PEVDNLTLDG NDFLVPGTAL PHEGSMNSGV VPACARSTLS VGVSGTLVLL QGARGEA GORILLA VQPHSLDLSH NSERATVNPS APRCMNSSAL NSLNLSFAGL EQVPKGLPAK LRVLDLSCNR LNRAPQPDEL PEVDNLTLDG NPFLVPGTAL PHEGSMNSGV VPACARSTLS VGVSGTLVLL QGARGFA

CHIMPANZEE VQPHSLDLSH NSLRATVNPS APRCMNSSAL NSLNLSFAGL EQVPKGLPAK LRVLDLSCNR LNRAPQPDEL PEVDNLTLDG NPFLVPGTAL PHEGSMNSGV VPACARSTLS VGVSGTLVLL QGARGFA

MONKEY VQPHSLDLSH NS_RATANPS APRCMNSSAL NSLNLSFAGL EQVPKGLPAK LRVLDLSCNR LNRRPRPDEL PQVDNLALDG NPFLVPGTAL PQEGSMNSGV VPACARSTLS VGVSGTLVLL QGARGEA

RABBIT VQPHHLDLSH NSLRADTQ-- --RCIWPSAL NSLNLSFTGL QQVPKGLPAK LNVLDLSCNK LNRAPQPGEL PKVVNLSLDG NPFLVPGASK LQEDLTNSGV FPACPPSPLA MGMSGTLALL QGARGET

HORSE VQPHSLDLSH NSSSAAA-PG APRCDWPSAL SSLNLSFAGL EQVPKGLPGK LSVLDLSCNR LNKAPRADEL PVVSNLILDR NPYLDPEASK QQD--QNSGV VAACAHSALT VGISGTLALL RGAGDFA

BOVINE VQPQSLDLSH NSLRVTA-PG ATRCVWPSAL RSLNLSFAGL EQVPKGLPPK LSVLDLSCNK LSREPRRDEL PEVNDLTLDG NPFLDPGALQ HQNDPMISGV VPACARSALT MGVSGALALL QGARGFA

YAK VQPQSLDLSH NSERVTA-PG ATRCVWPSAL RSLNLSFAGL EQVPKGLPPK LSVLDLSCNK LSREPRRDEL PEVNDLTLDG NPFLDPGALQ HQNDPMISGV VPACARSALT MGVSGALALL QGARGFA

BUFFALO VQPQSLDLSH NSIRVTA-PG ATRCVWPSAL RSLNLSFAGL EQVPKGLPPK LSVLDLSCNK LSREPRRDEL PEVNDLTLDG NPFLDPGALQ RQNDPMISGV VPACARSALT MGVSGALALL QGARGFA

SHEEP VQPQSLDLSH NSLRVT--PG ATRCVWPSAL SSLNLSFAGL EQVPRGLPTK LSVLDLSCNK LSREPRREEL PEVNVLTLDG NPFLDPGALK HQDDPMISGV VPACARSALT MGVSGTLALL QGARGEA

GOAT VQPQNLDLSH NSZRVTA-PG ATRCVNPSAI SSLNCSFAGL EQVPKGLPPK LSVLDLSCNK LSREPRRDEL PYVNVLTVNG NPFLDPGALQ HQNDPMISRM IPDRAPPSLV IGVSGALVLY QGARGEA

PIG VQPHRLDLSH NSLRATA-AG ARECVWPAAL SSLNLSFAEL EQVPRGLPPK LTVLDLSCNK LNRAPRPEEL PAVDDLTLEG NPYMDPEALQ HQEDPMASGV VPPCARSALT MGVSGTLALL QGARGFA

RAT VPLQALDLSH NSLRDTA--G TPSCDNPSQL NSLNLSETGL EHVPKGLPAK LSVLDLSYNR LDRRPRPEEL PEVGSLSLTG NPFLHSES--- -QSEAYNSGV VIATALSPGS AGLSGTLALL LGHRLFV

MOUSE VQLQGLDLSH NS_RDAA--G APSCDWPSQL NSLNLSETGL RQVPKGLPAR LSVLDLSYNR LDRNPSPDEL PQVGNLSLKG NPFLDSES-- -HSEKFNSGV VTAGAPSSQA VALSGTLALL LGDRLFV Consensus Vqph.LDLSH NSIrata.pg aprC.WpgaL nSLNLSFagL eqVPKGLPaK LsVLDLSCNr Lnr.PrpdEL P.V.nL.Ldg NPs\$dpga.. .q...mnSGV vpaca.S.1. .gvSGtLaLL qGargFa 


\section{Figure 2}

Phylogenetic tree of evolutionary relationships among taxa

The evolutionary history was inferred using the Neighbor-Joining method. The optimal tree with the sum of branch length $=1.48602764$. The tree is drawn to scale, with branch lengths in the same units as those of the evolutionary distances used to infer the phylogenetic tree. The evolutionary distances were computed using the p-distance method and are in the units of the number of amino acid differences per site. The analysis involved 14 amino acid sequences. The coding data were translated assuming a standard genetic code table. 


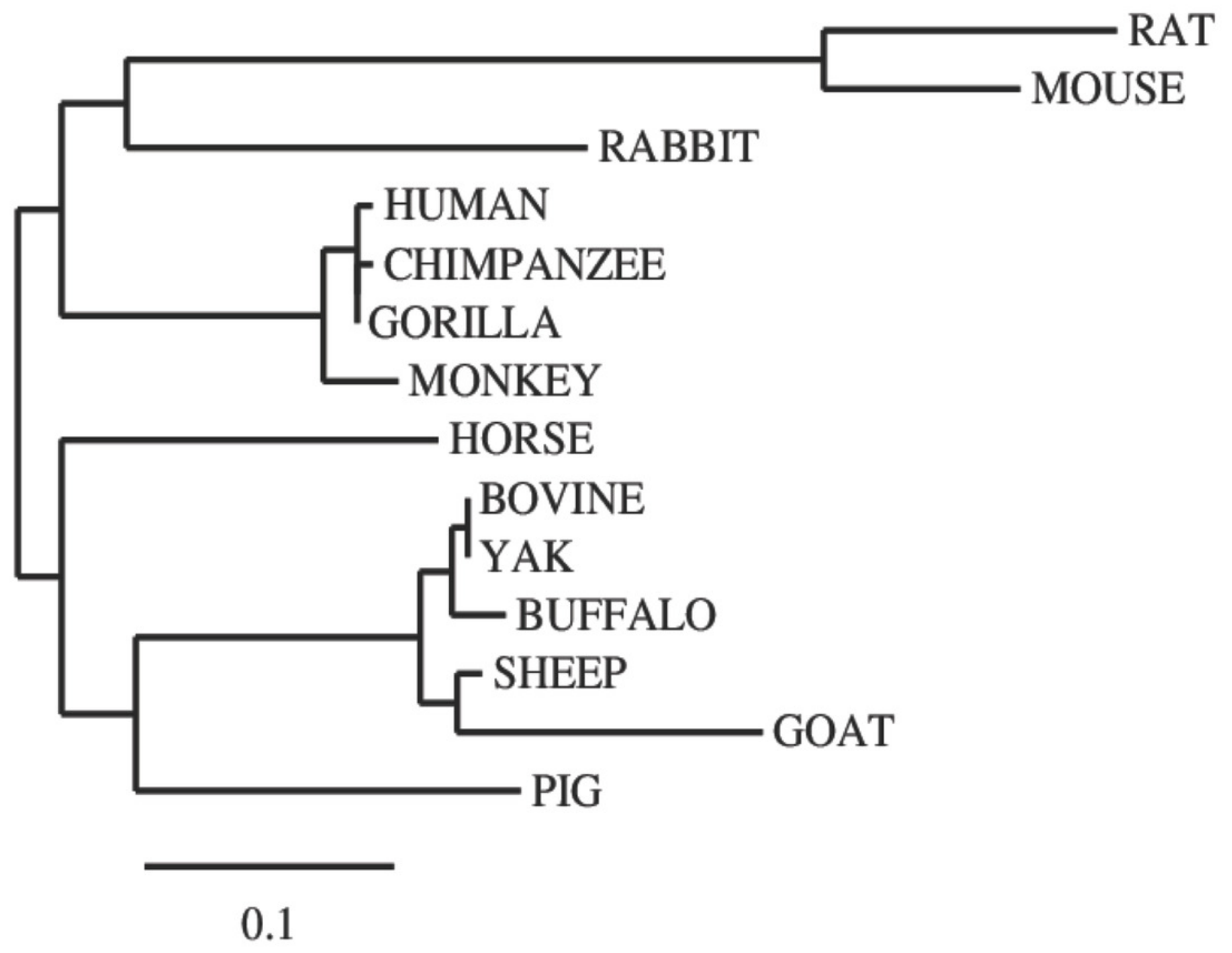


Figure 3

Comparison of predicted intra-domain features of CD14 protein

This comparison show leucine-rich repeat (PS51450), which provides additional information about the structure and function of critical amino acids in the 14 mammalian species 
ruler:

$\begin{array}{llllll}1 & 100 & 200 & 300 & 400 & 500\end{array}$

HUMAN

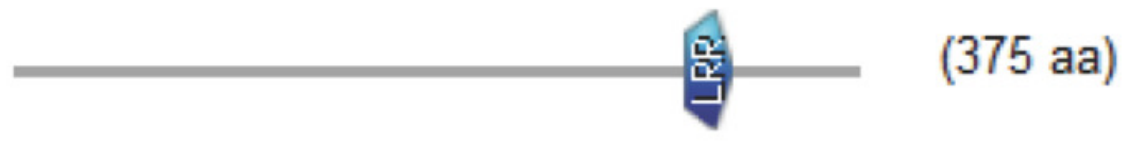

GORILLA

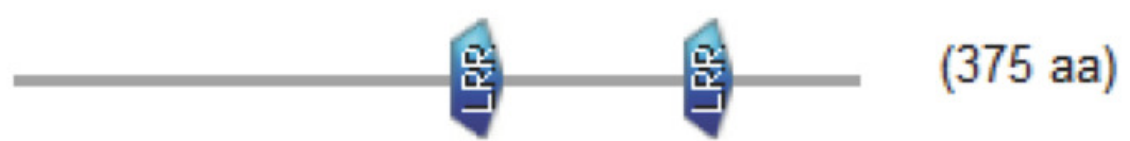

CHIMPANZEE

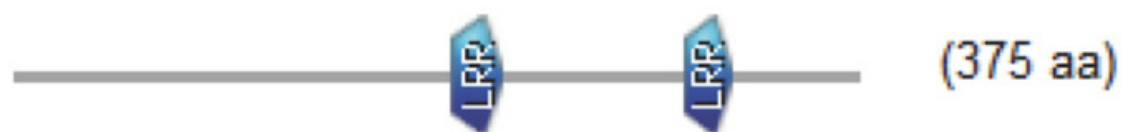

MONKEY

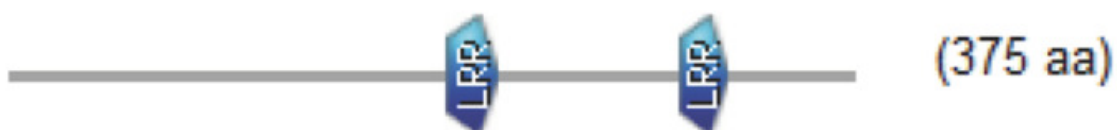

HORSE

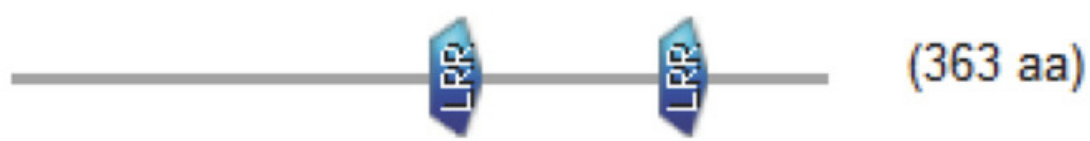

BOVINE

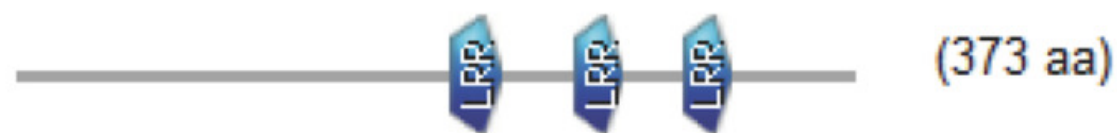

SHEEP

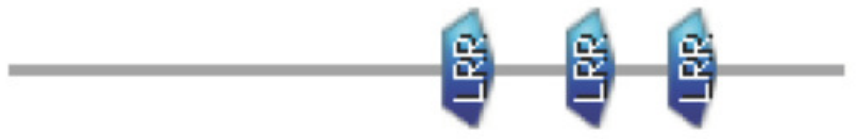

(371 aa)

BUFFALO

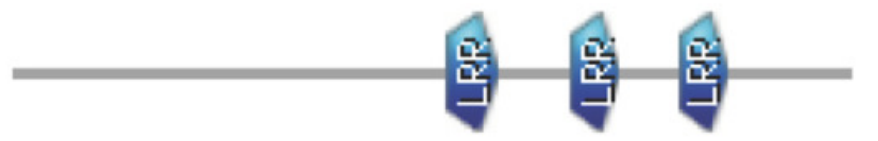

(373 aa)

YAK

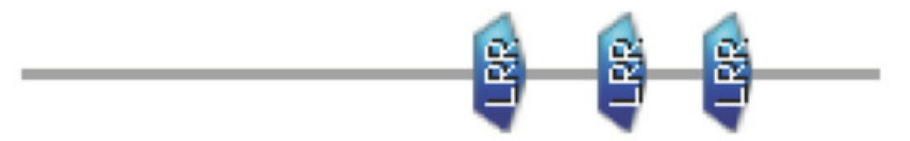

(381 aa)

GOAT

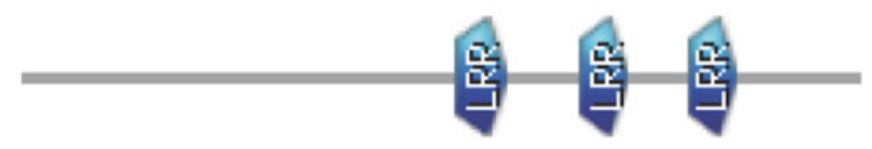

(373 aa)

PIG

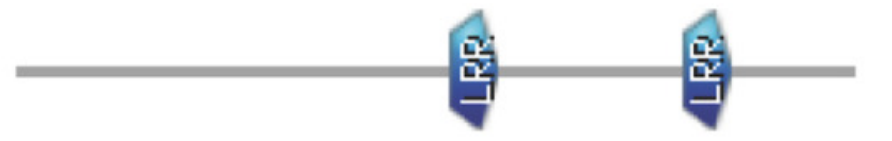

(373 aa)

RAT

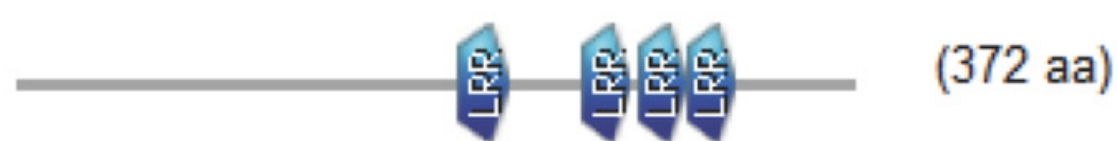

MOUSE

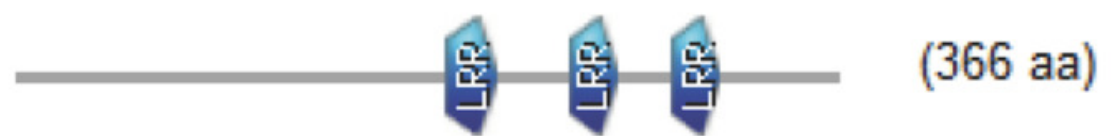


Figure 4

Conserved domain LRR patterns across mammalian species 
HUMAN

RAT

RAT_2 $^{2}$
$\mathrm{RAT}^{-3}$
$\mathrm{RAT}^{4} 4$

MOUSE

MOUSE_2

MOUSE 3

BOVINE

BOVINE 2

BOVINE_3

GOAT

GOAT_2

GOAT_3

MONKEY

MONKEY 2

GORILL $\bar{A}$

GORILLA_2

SHEEP

SHEEP 2

SHEEP 3

PIG

PIG 2

BUFFALO

BUFFALO 2

BUFFALO_3

CHIMPANZEE

CHIMPANZEE_2

YAK

YAK 2

YAK 3

HORSE

HORSE_2
KLRVLDLSCN . R. LNRAPQPDELP

ALATLDLSDNpE . LGEKGLISALC

PLQALDLSHN . S. LRDTAGTPSCD

KLSVLDLSYN. R. LDRKPRPEELP

QLNSLNLSFT . G. LEHVPKGLPA-

ALSTLDLSDNpE . LGERGLISALC

QLQGLDLSHN . S.LRDAAGAPSCD

KLSVLDLSYN. R.LDRNPSPDELP

ALTTLDLSDN. PsLGDSGLMAALC QPQSLDLSHN. S.LRVTAPGATRC KLSVLDLSCN . K. LSREPRRDELP

ALTTLDLSDN. PsLGDSGLMAALC QPQNLDLSHN. S.LRVTAPGATRC KLSVLDLSCN . K. LSREPRRDELP ALTSLDLSDN . PgLGERGLIAALC KLRVLDLSCN . R. LNRRPRPDELP ALTSLDLSDN. PgLGERGLIAALC KLRVLDLSCN . R. LNRAPQPDELP ALTTLDLSDN. PsLGDSGLMAALC QPQSLDLSHN . S . LRVTPGATRCV KLSVLDLSCN. K. LSREPRREELP ALTTLDLSDN . P. GLGERGLTAAL KLTVLDLSCN. K. LNRAPRPEELP ALTTLDLSDN. PsLGDTGLMAALC QPQSLDLSHN. S. LRVTAPGATRC KLSVLDLSCN . K. LSREPRRDELP

ALTSLDLSDNPgLGERGLIAALC KLRVLDLSCNR. LNRAPQPDELP ALTTLDLSDNPSLGDSGLMAALC QPQSLDLSHNS . LRVTAPGATRC KLSVLDLSCNK. LSREPRRDELP ALHTLDLSDNPgLGERGLIAALC KLSVLDLSCNR. LNKAPRADELP 
Figure 5

Figure 5: CD14 protein sequence logo displaying the most conserved domain and the positions of amino acids

Sequence logo displaying the most conserved domain and the positions of amino acids starting from the $\mathrm{N}$-terminus on the left to $\mathrm{C}$-terminus to the right. The relative frequency of the amino acids is shown on the $y$-axis.

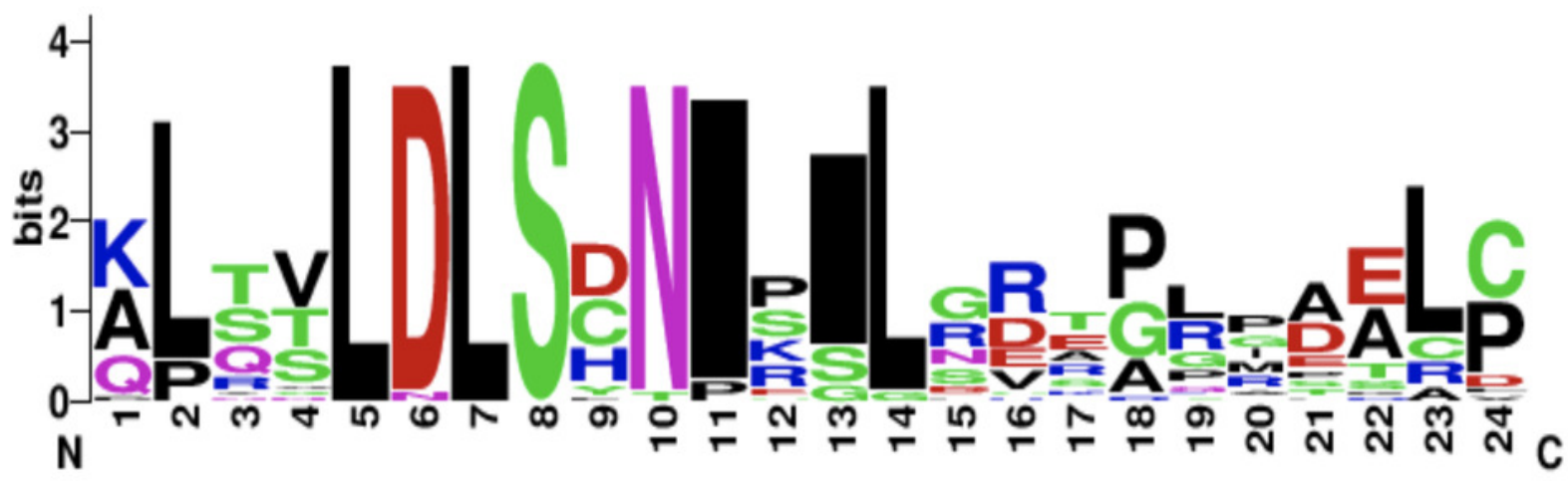




\section{Figure 6}

\section{Hierarchical tree-predicted subcellular localizations of CD14 protein using neural} networks algorithm

6A: Hierarchical tree for all other mammalian species analyzed

6B: Hierarchical tree for sheep only

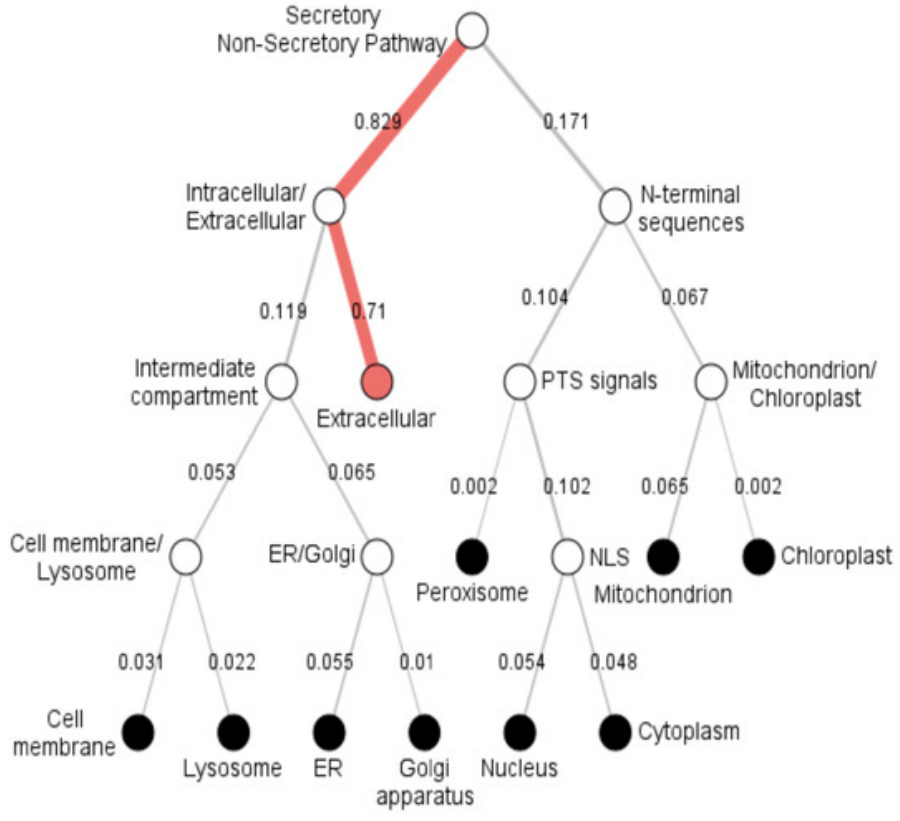

A

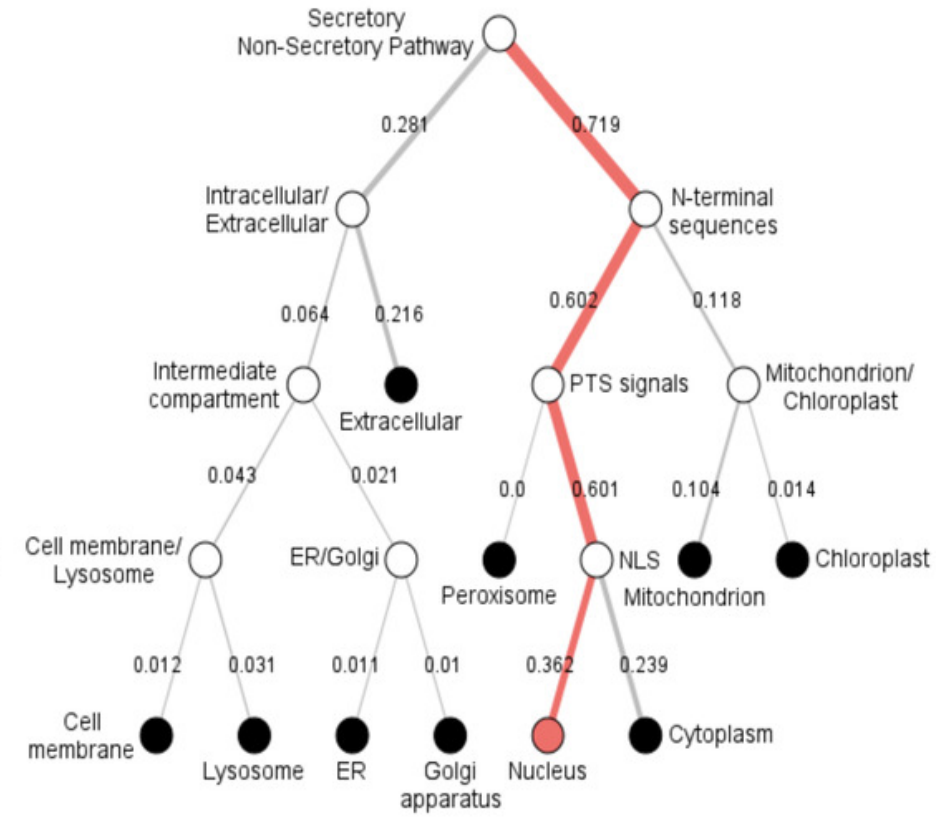

B 


\section{Figure 7}

Network view of predicted associations for group of proteins with CD14

The network nodes are proteins. The edges represent the predicted functional associations. The thickness of the line indicate the degree of confidence prediction for the interaction.

Red line: indicates the presence of fusion evidence Green line: neighborhood evidence

Blue line: co-occurrence evidence

Purple line: experimental evidence

Yellow line: text mining evidence

Light blue line: database evidence

Black line: co-expression evidence

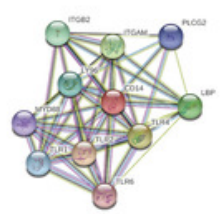

A

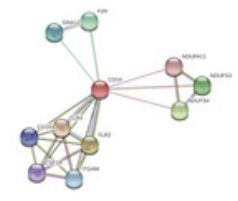

E

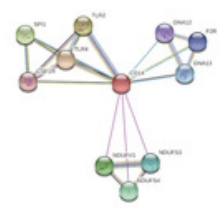

I

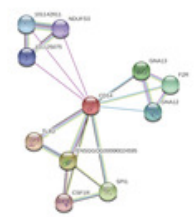

B

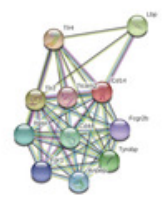

F

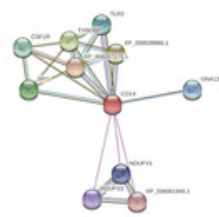

J

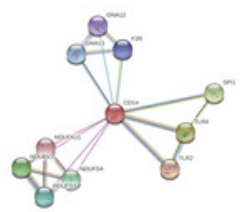

C

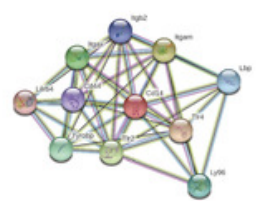

G

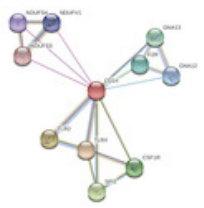

K

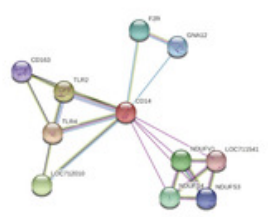

D

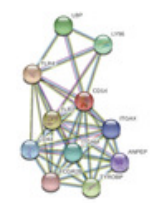

H

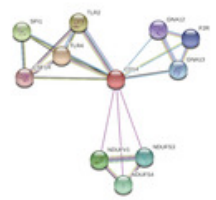

L

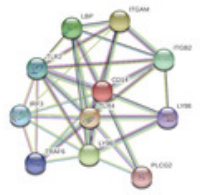

M 


\section{Figure 8}

Venn diagram showing the proportion of intersection and unique genes depicting evolutionary diversity of CD14 molecule

8A: Comparison and visualization of protein interaction with CD14 molecule in pig, rabbit, mouse and rat

8B: Comparison and visualization of protein interaction with CD14 molecule in cattle, yak, sheep, goat and buffalo

8C: Comparison and visualization of protein interaction with CD14 molecule in human, gorilla, chimpanzee and monkey

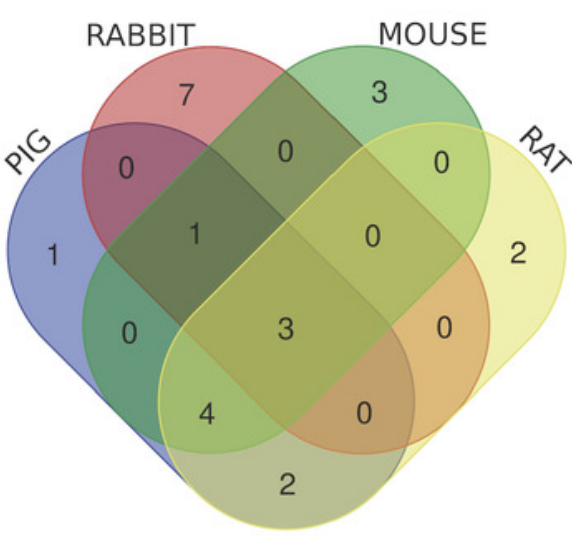

$\mathbf{A}$

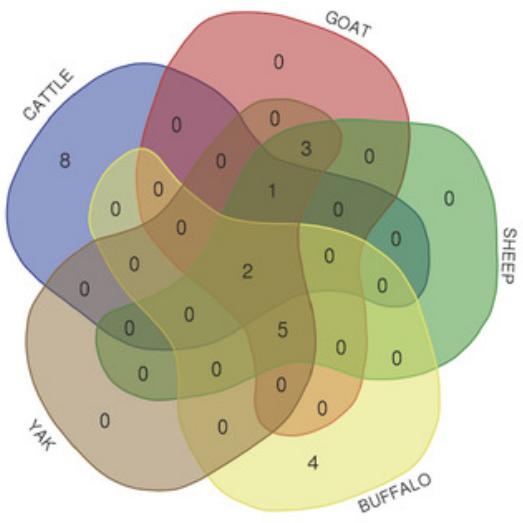

B

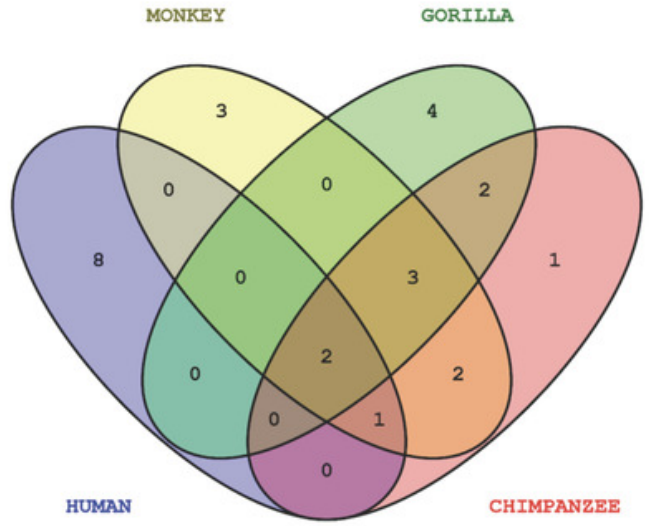

C 